International Journal of English Language and Literature Studies

$\operatorname{ISSN}(e): \quad 2306-0646$

$\operatorname{ISSN}(p): \quad 2306-9910$

DOI: $10.18488 / 5019 . v 1111.4419$

Vol. 11, No. 1, 31-41.

(C) 2022 AESS Publications. All Rights Reserved.

URL: www.aessweb.com

\section{TUNING LEARNING AND TEACHING STRATEGIES TO INDIVIDUAL DIFFERENCES AMONG LEARNERS OF ENGLISH IN ARAB UNIVERSITIES}

Bilal Zakarneh

\author{
Humanities and Social Sciences Research Center, Ajman University, Ajman, \\ UAE. \\ Email:zakarny@hotmail.com Tel:+971506499640
}

Article History

Received: 6 September 2021 Revised: 19 January 2022 Accepted: 2 February 2022 Published: 11 February 2022

\section{Keywords}

Adaptive teaching method Cooperative learning Individual differences L2 teaching

Language learning strategies Project-based learning.

\begin{abstract}
Teachers of English language in different contexts across the world use different strategies to cater to individual learner differences: diversified resources, spectrum of intelligences and multi-sensory experiences, tracking, adaptive teaching, etc. The present study investigated learning and teaching strategies applied by teachers of English in English as the second language (ESL) classes and those with a focus on Arab universities and the strategies to address unique individual student differences. This study reviewed the extant academic literature to identify the documented techniques used by teachers of English in different contexts with a focus on Arab university context. A structured questionnaire survey and Microsoft Excel were utilized to collect, analyze and present data respectively. Results revealed that distinct language learning behavior existed among learners of English in Arab universities: learning styles, personality, proficiency, intelligence, and motivation. As revealed in the results, particular strategies were employed by teachers of English in Arab universities to cater to individual differences among learners with adaptive teaching method as the most dominant technique. These strategies included project-based learning, classroom discussion, cooperative learning, and demonstrations, and other diverse learning materials. Teachers of L2 in Arab university can use these findings to understand what learners of English in L2 classroom needed, how they acquired and learned a language, and the ways to enhance quality learning using strategies that ensured that all learners could learn, gain maximum, and reach their full potential.
\end{abstract}

Contribution/ Originality: The primary contribution of this paper is that adaptive teaching methods, notably project-based learning, classroom discussions, cooperative learning, and demonstrations, as well as other diverse learning materials, can be widely embraced in English language classrooms in Arab universities to enhance and improve the L2 acquisition among learners of English.

\section{INTRODUCTION}

Learning a foreign or second language is challenging irrespective of whether it occurs in uninstructed settings or instructed settings (Pawlak, 2017). As suggested by Ellis (2010) the process and outcomes of learning a second language are affected by multiple unique factors, including the nature of instruction, the context of the foreign language, and individual, contextual, and linguistic difference variables. While researchers agree that all these factors pose a challenge to learning a foreign language, there is consensus that individual difference variables are vitally significant (Cohen \& Pinilla-Herrera, 2010; Pawlak, 2017). Pawlak (2017) identifies these individual factors 
as anxiety, beliefs, aptitudes, learning strategies, learning styles, cognitive, and motivation. Emphasizing the influential role of these individual differences in learning a second language, Ranta (2008) opined that learners of a foreign language tend to filter instruction via individual lenses, manipulate perceived information in different unique ways, and achieve understanding in various learning contexts and at different rates.

Zafar and Meenakshi (2012) also observed that individual learner differences exist among learners and that while some L2 learners make rapid and effortless progress, others progressed slowly and with great difficulty in learning the language. They further opined that these differences suggested that learners were not homogenous rather they differed in unique ways. Unique factors that brought these differences and affected the acquisition of L2 included cognitive style, motivation, personality, learning strategies, aptitude and gender. They also noted that these differences explained why some learners achieved near native speaker's level of foreign language competence while others did not progress beyond the beginner's level. In conclusion, they suggested that teachers of L2 should recognize individual differences among learners and use compatible and appropriate teaching methods.

This notion is further supported by evidence from experimental studies that learners' style of thinking and learning impact their acquisition of L2 (Oxford \& Amerstorfer, 2017). For example, Oxford and Amerstorfer (2017) contend that learners of L2 with learning styles that match instructional or teaching styles tend to retain information longer, hold positive attitudes towards the target language, and apply it more effectively than learners with clashing learning/teaching styles. Accordingly, educators in different contexts have attempted to apply learning and teaching strategies that cater to individual differences in the learning of a foreign language. While researchers have examined and identified specific learning strategies and styles largely favored by learners and teachers of L2, a majority undertook their studies largely within the context of Western countries, notably, the United States, Canada, and United Kingdom with speakers of other languages.

The above-mentioned few studies that investigated learning and teaching strategies employed by teachers of L2 within the Arab university context reported conflicting findings. On this basis, the present study examined learning and teaching strategies used by teachers of English in Arab universities to cater to individual differences among learners of English. This study is based on the premise that individual learner differences influence L2 acquisition and they act as factors responsible for differences in learning. There are evidence-based strategies found to be effective in meeting these individual learner's differences.

The present study enriches L2 teaching literature by identifying these individual learner differences among Arab learners of English and the learning and teaching strategies used by their teachers, and other strategies used elsewhere that can be adopted to enhance the teaching of L2 in Arab universities. Insight from the present study will help teachers of $\mathrm{L}_{2}$ in Arab universities to be sensitive to students' individual differences, create learning communities that reflect individual learners' needs, design lessons which appeal and motivate all learners of L2, develop positive teacher-student relationships, and maximize student's acquisition of L2.

\section{LITERATURE REVIEW}

Researchers have documented important points regarding learner-tailored strategies worth adopting in the L2 classroom to meet individual learner differences. Emphasis in the extant literature is placed on the importance of teachers of L2 understanding the language learning strategies defined by Oxford and Lavine (1992) as specific behaviors adopted by learners to enable them to learn a language. The argument is based on the view presented by Ehrman and Oxford (1990) that language learning styles (linked to personality types identified by Myers-Briggs) affects the learning strategies adopted and employed by individual learners.

\subsection{Language Learning Strategies}

Saito (2019) suggested that teachers of L2 need to differentiate their teaching strategies according to language learning strategies used by individual learners. He emphasizes that strategies in language learning determine the 
ultimate language performance. As described by Scarcella and Oxford (1992), language learning strategies are specific actions, techniques, steps, and behaviors used by learners to promote their learning. These strategies are identified as comprehension, social, affective, metacognitive, cognitive and memory (Scarcella \& Oxford, 1992).

Further, learners of L2 who embrace memory strategy rely on their ability to memorize content. They create a word-meaning map (mental linkages) in their brain as to aid getting the information in the long-term memory and to retrieve it easily. As proposed by Zafar and Meenakshi (2012) this memory strategy can be adopted to train learners to learn and retrieve information via images (i.e., meaning of a word or, mental picture of a word), sounds (e.g., rhyming), location (e.g., blackboard or page), mechanical means (flashcards), or body movement (total physical response). According to Zafar and Meenakshi (2012) teachers of L2 can help these types of learners learn by engaging them in a large number of English grammar exercises, asking them to create a word bank from reading material, watching TV shows and memorizing meanings of words while making attempts to use them.

Cognitive strategy is arguably appropriate for learners who analyze and reason. These learners learn by forming internal mental codes and revising them in an attempt to receive and create a message in the second (target) language. According to Oxford (2003) teachers of L2 can help learners to directly internalize language through analysis, reasoning, summarizing, note-taking, outlining, practicing structures, and practicing in naturalistic settings. Oxford (2003) further suggests that teachers can use this cognitive strategy to teach learners write letter or emails in L2, read L2 materials (e.g., newspapers and magazines), and watch drama in L2 and try to replicate the pronunciation of words.

Likewise, Dörnyei (2005) is of the opinion that comprehension strategy is fit for learners who practice guessing unknown words while reading and listening. These learners are known to make an attempt to replicate unfamiliar words with longer phrases or words they are familiar with when writing and speaking. This arguably helps them overcome gaps in knowledge. Dörnyei (2005) further suggests that teachers of language can use comprehensive strategy to help learners who learn language by guessing meaning of words they are not familiar with by enabling them to understand meaning by reading the entire comprehension passage in an attempt to guess the meaning of words and look at the words based on their context. For these learners, teachers of language are required to encourage them to look at nonverbal signs or cues when in conversation.

Metacognitive learning strategy is believed to suit learners who are adept at planning, focusing, arranging, and evaluating on their own learning process. These learners can identify and monitor their learning style needs and preferences, including collecting and organizing L2 material, scheduling for L2 revision, identifying and monitoring mistakes made in L2, arranging a study space, assessing the success of learning strategies, and evaluating the success of a task. In view of Dörnyei (2005), teachers of L2 can help these learners by asking them to observe how a language teacher speaks in L2, observe their own way of speaking in L2, and practice speaking in L2 while they are in front of a mirror. These learners can also be encouraged to engage in Google crosscheck of correct pronunciation. Teachers are also encouraged to ask these learners of L2 to play word games and complete crossword puzzles as well as take keen interest in how natives of $\mathrm{L} 2$ communicate.

Affective or social learning strategy is largely favored by learners with the ability to control their motivations, attitudes and feelings when participating in social situations like, when communicating with others, asking questions, interacting or facilitating conversation. To deal with these learners, Oxford and Ehrman (1992) propose that teachers of L2 should encourage them to speak in L2 and make them comfortable while they make mistakes, reward themselves when they perform well, exude confidence in speaking L2, and speak in L2 while communicating with others. These learners should also be motivated to ask for clarifications regarding any confusing words or jargons used in L2 and allow others to suggest the correction in their speech.

There is also another category of learners with the ability to utilize strategy chain: all the learning language learning strategies in the best combination. Strategy chain as contextualized by O'Malley and Chamot (1990) refers to language learning strategies that interlock, complement and mutually support each other. O'Malley and Chamot 
(1990) however, contend that while each individual learner utilizes every language learning strategy, some learners use certain learning strategies more frequently than they used others. Studies indicate no one strategy is dominant or more effective than another rather it depends on the learners' ability.

Studies emphasize the important role of teachers considering that different language learners have different predominant learning strategies. According to Oxford and Ehrman (1992) appreciating these differences in learners can help language teacher's plan lessons in a way that benefits every language learner. Oxford and Ehrman (1992) also hold that teachers of L2 can enable learners understand learning strategies and utilize a wide range of these strategies as it is beneficial for teachers to stretch learners' learning styles by facilitating them to make use of learning strategies which do not fall within the bounds of their primary preference. It is also worth noting that while learners use certain language learning strategies more than others, studies indicate that effective language learners employ an array of strategies. Oxford (1990) shows that optimal language learners tend to develop a combination of learning strategies that fit them and tailor their learning strategies to fit their needs.

\subsection{Strategies Used to Cater for Individual Differences in L2 Learning}

Studies have identified different strategies used by teachers of English in different contexts across the world to cater to individual learner differences: diversified resources, a spectrum of intelligences and multi-sensory experiences, tracking, adaptive teaching, and individualized instruction teaching.

\subsection{Differentiated Instruction or Differentiated Teaching}

Differentiated teaching or differentiated instruction involves teachers providing learners with alternative avenues for acquiring content, processing information, and demonstrating what is taught (Gregory \& Chapman, 2007). The concern of differentiated teaching is the academic achievement of small groups of learners and individual learners. The concern of teachers using differentiated teaching is the individual students' interests, learning ability, and historical and educational background. In this way, the teacher must choose the instructional techniques or strategies that best suit an individual learner (Ikwumelu, 2012).

Teachers who use differentiated resources often create a safe and nurturing learning classroom environment that allows learners to feel safe, accepted and willing to participate and take academic and personal risks (Kryza, Duncan, \& Stephens, 2010). This safe environment is created by teachers designating quiet work areas, offering material for learners to reflect on their personal and academic backgrounds, and set guidelines for learners to engage in independent work. These teachers also work with learners to help them discover appropriate and unique learning styles, and identify performance criteria (Kryza et al., 2010). Teachers who favor differentiated instruction are also known to tolerate some noise and movements in learning centers while, at the same time, actively monitoring the happenings in the classrooms at all times. These teachers also observed to establish a nurturing learning environment and to maximize learners' achievement using lessons which meet their needs during the learning process. They motivate learners along as far and quickly as possible by varying the product, process, and content based on the learners' learning profiles, interests and readiness.

\subsection{Tracking Teaching Method}

Tracking involves separating learners into groups for certain classes, subjects, or curriculum based on their achievement levels, IQ or perceived ability to accommodate varying needs of learners (Hallinan, 2000). Learners are placed in low, middle or high tracks and provided with the level of instruction and curriculum that fits their needs (Camblin, Gullatt, \& Shayna, 2003). Tracking is largely practiced in secondary schools in countries such as, Portugal, UK, US, Belgium, Switzerland, and Germany. In particular, learners with varied achievement levels in Switzerland, Belgium and Germany, go to separate secondary schools while in the UK, US and Portugal, learners attend the same school yet are grouped based on some subjects. Advocates of tracking believe that tracking method 
is efficient in addressing learners' different achievement needs by allowing teachers to assign struggling learners to low tracks and successful learners to high tracks (Camblin et al., 2003; The Education Trust, 2004). For Loveless (2002) this assigning of learners based on their achievement levels allows learners to perform according to their motivation and ability levels while allowing them to shift between the track ladder as their levels of achievement change. Loveless (2002) further argues that tracking model makes teaching of L2 easier by allowing teachers to pay attention to lessons on a certain level of instruction.

\subsection{Individualized Instruction Teaching}

Individualized instruction method involves self-paced learning and one-to-one teaching based on progressive goal's outline in accordance with the curriculum/course objectives. While much of instruction in individualized instruction occurs is in a group setting, membership to a learning group is never assumed to be permanent. The teachers help learners to learn in ways most suitable to them and segregating them between groups as needed. The teacher avoids assigning uniform requirements and assignment for the entire class (Ikwumelu, 2012). Each learner in individualized instruction teaching is assigned different tasks and support at an individual level based on the assumption that learners differ in individual needs. As further emphasized by Rukanuddin and Asfia (2016) the focus of individualized instruction method is the individual learner's needs as teaching tends to be specific targeting one need at a time. This teaching method is largely favored by teachers of special needs students as it allows the tutor to more effectively meet the learners' individual needs.

\subsection{Adaptive Teaching}

Adaptive teaching functions by encompassing the use of different instructional strategies that suit different groups of learners. It allows each learner to solve individual unique trouble spots by offering scaffolding customized to each learner. The overarching goal of this method is to ensure the natural diversity in classroom and help learners to succeed in spite of their varying learning styles, aptitude, and achievement levels (Borich, 2011). The teacher may use remediation approach to adaptive teaching or compensatory approach to adaptive teaching. The former is proactive in which the teacher enables the learner with prerequisite or basic skill or knowledge necessary for him/her to gain from planned instruction (e.g., question-and-answer session and student-centered discussion). The latter (compensatory approach) is reactive in that the instructional method is selected based on its effectiveness in compensating learners' lack of basic skill or knowledge. In this approach, the teacher may present content along with more learning activities and resources.

Adaptive teaching or learning can also make use of artificial intelligence and computer algorithms to orchestrate interactions among learners, and address unique needs of individual learners by delivering customized learning activities and resources (Haddad \& Kalaani, 2014). The overarching aim of using adaptive instruction is to achieve a learning environment that maximizes the learning outcome of an individual learner (Tsai \& Hsu, 2012). It involves considering individual differences among learners when teaching with the aim of achieving a common instructional objective. This method emphasizes the importance of teachers forming cognitive profiles of learners using learning styles (e.g., Felder-Silverman learning styles model, Felder-Solomon Index of learning styles models, Kolb Model, Myers-Briggs Type Indicator etc.). Teachers are then required to adapt their individual teaching styles to reflect learner's specific learning styles to optimize learning in a learner-centered classroom. According to Tsai and Hsu (2012) this adaptive teaching method is one of the methods that suits learner-centered second-language environment.

Based on the above studies, the following two study questions were framed:

1. What are the observable individual differences among learners of English in Arab Universities?

2. What learning and teaching strategies have been embraced by teachers of L2 classrooms in Arab universities to cater to individual differences among learners? 


\section{METHODOLOGY}

\subsection{Study Participants}

A total of 86 teachers of foreign language (English) in four Arab universities were recruited with vast majority $(85 \%)$ being males. The average teaching experience of the participants was 12.57 years with the range as 27 years, and shortest and longest teaching experience as 1 year and 28 years respectively. The majority of study participants (73\%) had worked as language instructors or teachers in Arab universities for a period exceeding 9 years inferring the sample as relatively experienced. Majority (86.5\%) of respondents noted that they participated in workshops on a regular basis to enhance their teaching knowledge and skill. However, the intensity and duration of such workshops and courses varied considerably.

\subsection{Data Collection Instrument}

A structured survey questionnaire was adopted distributed via e-email to teachers of English in Arab universities, their colleagues, and friends who were engaged in training teachers and could comfortably approach the practitioners or help in disseminating the questionnaire. Participants completed the questionnaires at their time of choice and subsequently returned by hand or electronically. Additional items covered in the questionnaire provided the basis for participants to describe their demographic information, and questions on possible strategies used by teachers of English in Arab universities. The focus was on individual differences observed among learners of English, approaches to teaching which cater individual learner differences, attempts made by teachers to tap into individual variations, extent to which teachers attempted to modify the learners' individual profiles.

\subsection{Validity and Reliability of the Survey Questionnaire}

The questionnaire validity and reliability have been confirmed in multiple studies studying L2 acquisition. In the present study the validity of the questionnaire was confirmed by comparing answers provided by respondents against those documented in the extant academic literature.

\subsection{Data Analysis Measures}

Quantitative data was summarized using a variety of numerical measures; percentage, or proportion of data values. Accordingly, the researcher quantified the Yes, No and N/B responses into percentages or proportion based on the scale items of the questionnaire that required teachers of L2 in four Arab universities to self-identify with aspects of learning and teaching strategies they used. The data so collected using these questionnaires were subjected to quantitative analysis using Microsoft Excel and converted into percentages presented in the next section in table formats and pie-charts.

\section{FINDINGS}

Respondents identified observable individual differences among learners of English as learning styles (41.8\%), personality (11.6\%), proficiency (12.4\%), intelligence $(9.1 \%)$ and motivation (15\%) and others $(21.1 \%)$. Other ID variables identified by respondents, include gender, first language, place of residence, aptitude, special education needs, family situation, and anxiety. Figure 1 summarizes these individual differences.

\subsection{Adaptive Teaching and Individualized Instruction}

Majority (85\%) of participants were less informed about adaptive teaching strategies and micro-adaptive approach to teaching. Surprisingly, these participants widely used (68\%) adaptive and micro-adaptive strategies in their L2 classrooms yet majority (75\%) were not sure whether doing so helped achieve a learning environment that maximized the learning outcomes for an individual learner. Indeed, majority (60\%) of participants confirmed that they used some of the adaptive teaching strategies, notably project-based learning, classroom discussion, 
cooperative learning, and demonstrations, as well as using diverse learning materials. However, only $13 \%$ of participants offered their learners alternative strategies and procedures for instruction.

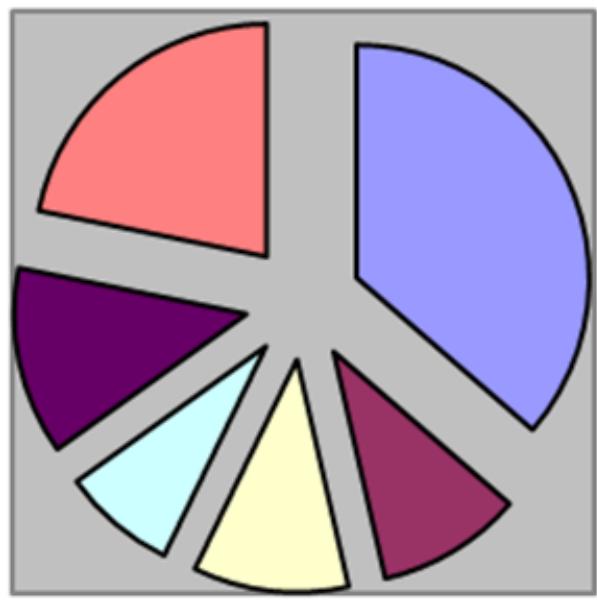

\begin{tabular}{|l|}
\hline QLearning style \\
$\square$ Personality \\
$\square$ Proficiency \\
QIntelliegence \\
QMotivation \\
QOthers \\
\hline
\end{tabular}

Figure 1. Individual differences among learners of English.

Few of the participants (2\%) made use of artificial intelligence and computer algorithms to orchestrate interactions among learners, and address unique needs of individual learners. Furthermore, only a few participants $(12 \%)$ claimed to assign different tasks and support at an individual level. Table 1 presents all responses pertaining to Adaptive Teaching and Individualized Instruction.

Table 1. Responses regarding the use of adaptive teaching strategies and individualized instructions.

\begin{tabular}{|c|c|c|c|}
\hline \multirow{2}{*}{ Statement } & \multicolumn{3}{|c|}{ Responses } \\
\hline & Yes & No & N/B \\
\hline $\begin{array}{l}\text { I understand adaptive teaching strategies and micro-adaptive approach } \\
\text { to teaching }\end{array}$ & $12 \%$ & $85 \%$ & $3 \%$ \\
\hline $\begin{array}{l}\text { I use adaptive teaching strategies and micro-adaptive approach to } \\
\text { teaching }\end{array}$ & $68 \%$ & $21 \%$ & $11 \%$ \\
\hline I offer learners alternative strategies and procedures for instruction & $13 \%$ & $74 \%$ & $13 \%$ \\
\hline $\begin{array}{l}\text { I embrace project-based learning, cooperative learning, classroom } \\
\text { discussions, and demonstrations and use diverse learning materials } \\
\text { when teaching my students }\end{array}$ & $60 \%$ & $33 \%$ & $7 \%$ \\
\hline $\begin{array}{l}\text { I make use of artificial intelligence and computer algorithms to } \\
\text { orchestrate interactions among learners, and address unique needs of } \\
\text { individual learners }\end{array}$ & $2 \%$ & $83 \%$ & $15 \%$ \\
\hline $\begin{array}{l}\text { I use adaptive learning to achieve a learning environment that } \\
\text { maximizes the learning outcome of an individual learner }\end{array}$ & $75 \%$ & $22 \%$ & $3 \%$ \\
\hline I assign different tasks and support at an individual level & $12 \%$ & $85 \%$ & $3 \%$ \\
\hline
\end{tabular}

\subsection{Differentiated Instruction/Differentiated Teaching}

Differentiated instruction or differentiated teaching is hardly embraced by teachers of English in Arab universities. While few (13\%) of the teachers out of the sample held that they understood and used different modes of instruction or different teaching methodologies in their English classrooms, a vast majority (85\%) indicated that they never used this strategy. Confirming that they understood what characterizes differentiated teaching, only $15 \%$ of the participants agreed (Yes $=15 \%$ ) that they allowed learners to choose how they learned with others (individually, with a whole class, in small groups, or in pairs).

Similarly, a small number of participants (Yes $=8 \%$ ) agreed with the statement, "I allow learners to choose the difficult levels of assignments using activity menus, interactive learning menus, choice boards or other menu-based tools". Consistent with other responses, some participants agree with the following statements: I allow learners to choose 
what they study, the quiz questions they answer, and what when, how and where they learn (Yes=14\%); I make assessments in the class to gauge learners' progress (Yes=11\%); I offer high-and no-tech scaffolding for reading (Yes=13\%), and I provide targeted scaffolding (e.g., SAS Writing Reviser, word bank of transitions) to learners (Yes=14\%). These responses are tabulated in Table 2.

Table 2. Participants' understanding and use of differentiated instruction or differentiated teaching.

\begin{tabular}{|c|c|c|c|}
\hline Statement & Yes & No & $\mathbf{N} / \mathbf{B}$ \\
\hline $\begin{array}{l}\text { I allow learners to choose how they learn with others (individually, with a } \\
\text { whole class, in small groups, or in pairs) }\end{array}$ & $15 \%$ & $79 \%$ & $6 \%$ \\
\hline $\begin{array}{l}\text { I allow learners to choose the difficult levels of assignments using activity } \\
\text { menus, interactive learning menus, choice boards or other menu-based tools }\end{array}$ & $8 \%$ & $75 \%$ & $17 \%$ \\
\hline $\begin{array}{l}\text { I allow learners to choose what they study, the quiz questions they answer, } \\
\text { and what when, how and where they learn }\end{array}$ & $14 \%$ & $84 \%$ & $2 \%$ \\
\hline I bake assessments in the class to gauge learners' progress & $11 \%$ & $81 \%$ & $8 \%$ \\
\hline I use differentiated Instruction or differentiated teaching in my English class & $13 \%$ & $85 \%$ & $2 \%$ \\
\hline I offer high-and no-tech scaffolding for reading & $13 \%$ & $77 \%$ & $10 \%$ \\
\hline $\begin{array}{l}\text { I provide targeted scaffolding (e.g., SAS Writing Reviser, word bank of } \\
\text { transitions) to learners }\end{array}$ & $14 \%$ & $78 \%$ & $8 \%$ \\
\hline
\end{tabular}

\subsection{Tracking}

Another finding of this study is that tracking is less favored method in Arab universities as participants overwhelmingly and affirmatively denied its use $(\mathrm{No}=98 \%)$ as imbedded in the statement, "learners of English at different levels of achievement attend separate universities". Equally, participants (No=97\%) did not approve of the statement that learners of English at different levels attend the same class but are grouped based on their abilities and levels of proficiency.

Additionally, participants disagreed with $\left(\mathrm{No}_{0}=95 \%\right)$ the statement that they grouped/placed students according to their perceived ability, IQ, or achievement levels into: high, middle, and low tracks. Participants also held an opinion contrary $(\mathrm{No}=95 \%)$ to the statement that learners of English in Arab universities are grouped into tracks based on the similarity or differences in their levels of achievement. Responses to this factor are presented in Table 3 .

Table 3. Participants' responses regarding their knowledge and use of tracking method.

\begin{tabular}{|c|c|c|c|}
\hline Statement & Yes & No & $\mathbf{N} / \mathbf{B}$ \\
\hline Learners of English at different levels of achievement attend separate universities & $0 \%$ & $98 \%$ & $2 \%$ \\
\hline $\begin{array}{l}\text { Learners of English at different levels attend same class but are grouped based on } \\
\text { their abilities and levels of proficiency }\end{array}$ & $0 \%$ & $97 \%$ & $3 \%$ \\
\hline $\begin{array}{l}\text { I group/place my students according to their perceived ability, IQ, or achievement } \\
\text { levels: high, middle, and low tracks }\end{array}$ & $1 \%$ & $95 \%$ & $4 \%$ \\
\hline Our learners are grouped based on their ability or level of proficiency of language & $2 \%$ & $95 \%$ & $3 \%$ \\
\hline
\end{tabular}

\subsection{Other Teaching Strategies}

While participants stressed the importance of addressing individual learners' differences by making attempts to plan and undertake their teaching in a way that ensures comparable opportunities for learners by manifesting different learning styles (Yes=55\%), adjust pace of activities to match learners' capabilities (Yes=57\%), and include additional activities for better learners (Yes=52\%), these respondents candidly stated that they were not in a position to address and consider students' individual profiles in their teaching. Again, some respondents held that they were not in a position to assign tasks designed for different levels of difficulty (No=70\%), differentiate assessment criteria $\left(\mathrm{No}_{\mathrm{O}}=77 \%\right)$, and use differentiation when implementing tasks and activities through pair and group work $(\mathrm{No}=76 \%)$. These responses are summarized in Table 4: 
Table 4. Participants' response regarding their knowledge and use of other teaching methods.

\begin{tabular}{|c|c|c|c|}
\hline Statement & Yes & No & $\mathbf{N} / \mathbf{A}$ \\
\hline $\begin{array}{l}\text { I plan and conduct lessons in a way that ensures comparable opportunities for } \\
\text { learners manifesting different learning styles }\end{array}$ & $55 \%$ & $35 \%$ & $10 \%$ \\
\hline Adjust pace of activities to match learner's capabilities & $52 \%$ & $38 \%$ & $10 \%$ \\
\hline Match learners in different ways during group and pair work activities & $57 \%$ & $37 \%$ & $6 \%$ \\
\hline I consider students' individual profiles in my teaching & $9 \%$ & $74 \%$ & $17 \%$ \\
\hline Assign tasks at different levels of difficulty & $15 \%$ & $70 \%$ & $15 \%$ \\
\hline Include additional activities for better learners & $52 \%$ & $32 \%$ & $16 \%$ \\
\hline I differentiate assessment criteria & $12 \%$ & $77 \%$ & $11 \%$ \\
\hline $\begin{array}{l}\text { I use differentiation when implementing tasks and activities through pair and group } \\
\text { work }\end{array}$ & $17 \%$ & $76 \%$ & $7 \%$ \\
\hline Ask more proficient learners to act in tutors' capacity & $11 \%$ & $73 \%$ & $16 \%$ \\
\hline
\end{tabular}

\section{CONCLUSION}

The present study investigated learning and teaching strategies employed by teachers of English as L2 classrooms in Arab universities to address unique individual students' differences. Results show that individual differences exist among learners of English in Arab universities. Notable individual differences identified in this study are learning styles, personality, proficiency, intelligence, and motivation. This study also showed that although there seems to be no particular strategies being employed by teachers of English in Arab universities to cater to individual differences among learners, teachers seem to incline towards the adaptive teaching method as evidenced in the use of the project-based learning, classroom discussion, cooperative learning, and demonstrations, and other diverse learning materials.

Speculatively, these participants follow the guidelines of the policy makers to use strategies that reflect adaptive and micro-adaptive teaching strategies. These strategies are known to work to cater to individual learner differences as reinforced by Haddad and Kalaani (2014). They see adaptive teaching as a useful technique that can be used by teachers of L2 to micro-adapt their instruction to individual student needs. The authors further emphasized that adaptive teaching allows the teacher to assess and capitalized on the learners' weaknesses and strengths to help them become self-regulated. This is achieved by the teacher delivering individual learner tailored content through assigning different tasks to different learners. This allows some learners to work independently, others to get introduced to new concepts as they engage in learning with peers. In this way, low-achieving learners can receive more structured support and guidance from teachers than high-achieving learners with the ability to work independently.

While adaptive teaching seems to work in some settings, this strategy is thought to work more effectively in catering to individual learner differences when used in combination or complemented by other strategies namely differentiated instruction, individualized instruction, and tracking (The Education Trust, 2004). This view is reinforced by Baer, Kocher, and Wyss (2009) that a combination of these strategies allows the teacher of L2 to address learners' specific and unique needs, interests and abilities accommodated in differentiated instruction, individualized instruction and tracking. Baer et al. (2009) further opine that a curriculum that considers a combination of these strategies will be sufficiently rigorous, coherent and challenging for all learners of L2. Moreover, strategies such as differentiated instructional practices can motivate learners and increase their achievement by allowing teachers to teach students in ways that reflect their readiness levels, learning profiles, and interests.

According to Zywno (2002) adjustments should be made to lessons offered in the L2 classroom such that assignments provided to learners encompass questions that vary in the level of difficulty. The teaching method should permit some learners to be graded tighter than others, permit earlier learners and native speakers of the language to tutor their peers, let learners who complete early engage in games for enrichment (Karnes \& Bean, 2001). 
Pedagogically, teachers of L2 in Arab universities need to embrace and create a more efficient learner-centered second-language learning environment, seek to understand individual learners' cognitive profiles to adapt their teaching styles accordingly, create a learner-centered classroom environment that allows for learner flexibility, choice, and independence. Moreover, they should encourage sincere exploration and innovation, and allow for creating various grouping arrangements and high mobility in the classroom.

Funding: This study received no specific financial support.

Competing Interests: The author declares that there are no conflicts of interests regarding the publication of this paper.

\section{REFERENCES}

Baer, M., Kocher, M., \& Wyss, C. (2009). Can teaching be learned? --Acquiring teaching competencies during teacher training and first year in training. Paper presented at the American Educational Research Association Annual Meeting. San Diego, CA.

Borich, G. D. (2011). Effective teaching methods. Boston: Pearson Education, Inc.

Camblin, S., Gullatt, Y. K., \& Shayna, B. (2003). Strategies for success: Six stories of increasing college access. Boston, MA: Pathways to College Network.

Cohen, A. D., \& Pinilla-Herrera, A. (2010). Communicating grammatically: Constructing a learner strategies website for Spanish. In T. Kao \& Y. Lin (Eds.), A new look at language teaching and testing: English as subject and vehicle (pp. 63-83). Taipei, Taiwan: The Language Training and Testing Center.

Dörnyei, Z. (2005). The psychology of the language learner: Individual differences in second language acquisition. Mahwah, NJ: Lawrence Erlbaum.

Ehrman, M., \& Oxford, R. (1990). Adult language learning styles and strategies in an intensive training setting. The Modern Language Journal, 74(3), 311-327.Available at: https://doi.org/10.1111/j.1540-4781.1990.tbo1069.x.

Ellis, R. (2010). Epilogue: A framework for investigating oral and written corrective feedback. Studies in Second Language Acquisition, 32(2), 335-349.

Gregory, G. H., \& Chapman, C. (2007). Differentiated instructional strategies: One size doesn't fit all (2nd ed.). Thousand Oaks, CA: Corwin.

Haddad, R. J., \& Kalaani, Y. (2014). Adaptive teaching: An effective approach for learner-centered classrooms. Paper presented at the ASEE International Forum, Indianapolis, Indiana. 10.18260/1-2--17166.

Hallinan, M. T. (2000). Ability group effects on high school learning outcomes. Brookings Papers on Education Policy, 6(3), 95-140. Ikwumelu, S. N. (2012). Dictionary of social studies and civic education. Owerri: Living Seed Publishers Ltd.

Karnes, F. A., \& Bean, S. M. (2001). Methods and materials for teaching the gifted. Waco, TX: Prufrock Press.

Kryza, K., Duncan, A., \& Stephens, S. J. (2010). Di-erentiation for real classrooms. Thousand Oaks, CA: Corwin Press.

Loveless, T. (2002). The tracking and ability grouping debate, Thomas Fordham foundation. NASSP, 2004, Breakthrough High Schools: You Can Do It Too, Reston,VA.

O'Malley, J. M., \& Chamot, A. U. (1990). Learning strategies in second language acquisition. Cambridge: Cambridge University Press.

Oxford, R., \& Lavine, R. (1992). Teacher-student style wars in the language classroom: Research insights and suggestions. ADFL Bulletin, 23(2), 38-45.

Oxford, R. L. (1990). Language learning strategies: What every teacher should know. Boston, MA: Heinle \& Heinle.

Oxford, R. L., \& Amerstorfer, C. M. (2017). Language learning strategies and individual learner characteristics: Situating strategy use in diverse contexts. London: Bloomsbury.

Oxford, R. L. (2003). Language learning styles and strategies: An overview. Oxford: GALA.

Oxford, R. L., \& Ehrman, M. (1992). Second language research on individual differences. Annual Review of Applied Linguistics, 13(3), 188-205. 
Pawlak, M. (2017). Individual difference variables as mediating influences on success or failure in form-focused instruction. In E.

Piechurska-Kuciel, E. Szymańska-Czaplak, \& M. Szyszka (Eds.), At the crossroads: Challenges of foreign language learning (pp. 75-92). Heidelberg: Springer Nature.

Ranta, L. (2008). 'Aptitude and good language learners' in C. Griffiths (ed.). Lessons from Good Language Learners. Cambridge: Cambridge University Press.

Rukanuddin, M., \& Asfia, R. (2016). Knowledge of individual differences of the learners of second language enriches second language teaching. Journal of Literature, Languages and Linguistics, 19(2), 11-24.

Saito, K. (2019). Individual differences in second language speech learning in classroom settings: Roles of awareness in the longitudinal development of Japanese learners' English /. / pronunciation. Second Language Research, 35(2), 149172.Available at: https://doi.org/10.1177/0267658318768342.

Scarcella, R., \& Oxford, R. (1992). The tapestry of language learning: The individual in the communicative classroom. Boston: Heinle \& Heinle.

The Education Trust. (2004). The real value of teachers, thinking K-16, 8(1). Washington: The Education Trust, Inc.

Tsai, C. C., \& Hsu, C. Y. (2012). Adaptive instruction systems and learning. In: Seel N.M. (Eds.), Encyclopedia of the Sciences of Learning. Boston, MA: Springer.

Zafar, S., \& Meenakshi, K. (2012). Individual learner differences and second language acquisition: A review. Journal of Language Teaching and Research, 3(4), 639-639.Available at: https://doi.org/10.4304/jltr.3.4.639-646.

Zywno, M. S. (2002). Improving student outcomes through hypermedia instruction -a comparative study. British Journal of Engineering Education, 3(2), 25-33. 